\title{
Measuring Gratification of Social Media Use in Kazakhstan Using Niche Theory
}

\author{
Heon Baek ${ }^{1}$, Ha Jin Hwang ${ }^{2}$ \\ ${ }^{1}$ Ph.D. Student, School of Business Administration, Sogang Univ, Seoul. Korea \\ ${ }^{2}$ Professor, Operations Management and Information Systems and Dean of Bang \\ College of Business, KIMEP University, Kazakhstan \\ hunny01017@hanmail.net,hjhwang@kimep.kz.
}

\begin{abstract}
With the wide availability of portable mobile devices, social media has become a main tool for information sharing and communication recently. In Kazakh tan it is also noticed that the usage of social media has been continuously increasing and social media is easily available. There have been many previous researches on how social media play roles of availability for tasks using media richness theory, social existence theory, how well social media can represents the characteristics of face to face communication, and how richness of media affect the communication on social media. However, there arenot many studies conducted on the difference in the gratification of soctal media reflecting unique features and characteristics of social media.

This study examined gratification of social medtatitizing limited resources based on four important factors using niche theor. Niche theory employs niche width, niche overlap, and superiority to analyze the degxee of competencrof each social media based on each criteria. This study is expected to identify market structure of social media in Kazakhstan and provide an opportunity for general oyerview of competency in social media market in the developing countries.

The limitation of this study is basically dependent upon samples from university students. Consequently, it seems to be difficult to generalize the result of the study to apply to all user groups representing diverse age groups. It is desirable and recommended to conduct further research to specify the level of previous experiences and consider personal characteristics.
\end{abstract}

Keywords: social media, niche theory, user gratification

\section{Introduction}

Recently, is observed that the transition from the traditional communication methods to media based communication using internet and mobile devices are rapidly increasing. In Kazakhstan it is also noticed that the usage of social media has been continuously increasing and social media is easily available. Thanks to its availability over portable mobile devices, social media has become a main tool for information sharing and communication. This trend has contributed to not only the flow of information but also the development of social relationship.

According to the previous researches, there have been many studies on how social media play roles of availability for tasks using media richness theory, social existence theory, how well social media can represents the characteristics of face to face communication, and how richness of media affect the communication on social media. However, there are not many 
researches conducted on the difference in the gratification of social media reflecting unique features and characteristics of social media.

This study is conducted to explore the relationship of competency among social media using niche theory. This study is expected to identify market structure of social media in Kazakhstan and provide an opportunity for general overview of competency in social media market in the developing countries.

\section{Literature Review}

\subsection{SNS and Social Relationship}

Social Network Service(SNS) is a kind of service over the internet and mobile devices, which enables users to share opinions, knowledge and information as well as various interaction and feedback over the social networks. Among many SNS, this study is focused on Blog, Facebook, Twitter, and Youtube. Facebook is one of the most popular SNS sites which can allow people to upload and share photos, video, and audjo files. It also provides communication capability through emails and instant messagng services [1, 2]. Blog is considered to be early version of SNS. This SNS is specian types of SNS based on reverse chronological order (OECE, 2007). Blogs can be managed individually but interaction can be provided by adding comments on other peoples' feedback [1]. Twitter is a type of SNS and also known to be microblog. It provides the capability of profile page as well as some personal information. This SNS service enables people to update messages using mobile phones and web, so is called microblogging [3]. Youtube is a type of SNS based on video type contents communities. The main idea of this SNS isto share media contents among users [1].

\subsection{Media Richness and Social Presence}

Media richness is determined by factors such as instant feedback, multiple cues, language variety, and personal focu. Media richness theory is focused on the research on how the gratification of social media use is affected by the richness of various computer based devices [4]. A recent study reveared that a positive impact on SNS rewards was achieved by the media richness [5].

Social presence is a concept to explain the psychological experience which is formed through interaction among users in the internet environment. It is typically a capability of social media which enables users to feel the existence of other people [6].

The degree of social presence is dependent upon how well the media can deal with non language messages. It will be very helpful to improve the social presence when the media can provide socially rich material, virtual communities, online message board, online chat system, email after-sales support [7].

As shown in the following table 1, Kaplan and Haenlein [1] has expressed the degree of self-presentation based on social presence and media richness. It was revealed that text based blog-and collaborative projects such as Wikipedia are turned out to be low in social presence and media richness. Youtube and Facebook which are using animation, photos, and video contents are determined to be medium in terms of social presence and media richness while vitual social worlds and game environment are turned out to be high in social presence and media richness being similar to face to face communication. 
Table 1. The Degree of Self-Presentation based on Social Presence and Media Richness

\begin{tabular}{|c|c|c|c|c|}
\hline & \multicolumn{3}{|c|}{ Media Richness / Social Presence } \\
\hline & & Low & Medium & High \\
\hline \multirow{2}{*}{$\begin{array}{c}\text { Self - } \\
\text { presentation } \\
\text { / Self - } \\
\text { disclosure }\end{array}$} & High & Blogs & $\begin{array}{c}\text { Social networking } \\
\text { sites }\end{array}$ & $\begin{array}{c}\text { Virtual social } \\
\text { worlds }\end{array}$ \\
\hline & Low & $\begin{array}{c}\text { Collaborative } \\
\text { projects }\end{array}$ & $\begin{array}{c}\text { Content } \\
\text { communities }\end{array}$ & $\begin{array}{c}\text { Virtual game } \\
\text { worlds }\end{array}$ \\
\hline
\end{tabular}

\section{Research Model and Research Methodology}

\subsection{Research Model}

This study is designed to explore how competent social media in Kazakhstan are in satisfying users' expectation and how they can be compared each other in terms of information inquiry, social relationship, social presence, and media richness. The niche theory is used to measure the gratification of social media such as. Facebook, Blog, Twitter, and Youtube. The research model is presented in the Figare 1. The research nodel is designed to identify important factors which affect gratification of use over social média.

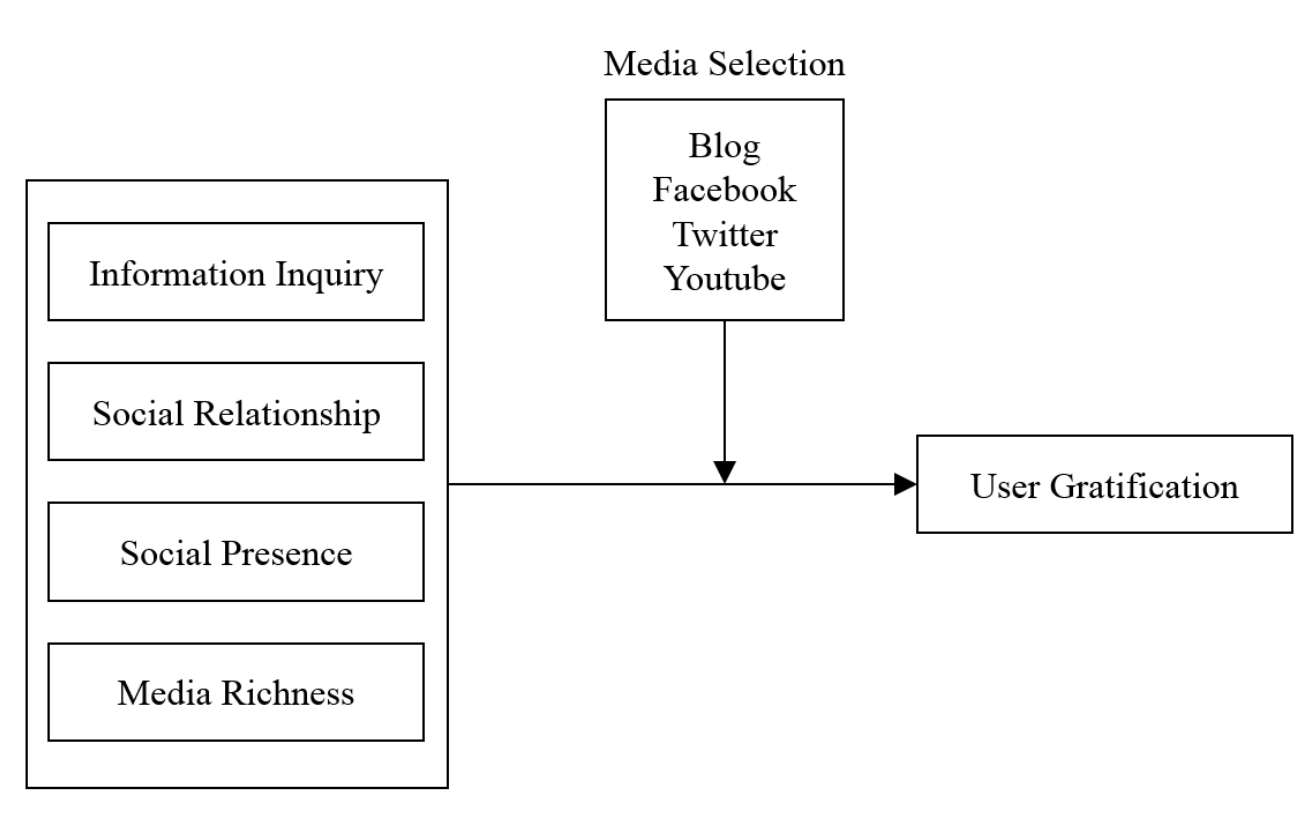

Figure 1. Research Model

\subsection{Niche Theory}

Niche theory is focused on the implication that various media can create a niche market to maintain competence dealing with limited resources [8,9]. The level of competence is dependent upon niche breadth, niche overlap, and competitive superiority which each media demonstrates. Niche breadth is a standardized number in the range of $0 \sim 1$. The closer the niche breadth to 1 , the better the social media is capable of satisfying user's expectation, consequently indicates more highly used media.

Niche Breadth can be measured based on the equation as follows. 
$B=\frac{\sum_{n=1}^{N}\left\{\frac{\sum_{k=1}^{K} G O_{n}-K I}{K(u-1)}\right\}}{N}$

$\mathrm{u}, 1=$ the upper and lower bounds of a scale

$\mathrm{GO}=$ a gratification obtained rating on a scale

$\mathrm{N}=$ the number of respondents using a medium

$\mathrm{n} \quad=$ the first respondent

$\mathrm{K}=$ the number of scales on a dimension

$\mathrm{k}=$ the first gratification scale

Niche Overlap is the measurement of the similarity of the patterns how vanous media utilize resources. It indicates the degree of dependency of different mediat on the same resource. It can measured by the formula below, meaning that the lower the number, the higher the overlap each other.

$O_{i, j}=\frac{\sum_{n=1}^{N} \sqrt{\sum_{k=1}^{K} \frac{\left(G O_{i}-G O_{j}\right)^{2}}{K}}}{N}$

$\mathrm{i}, \mathrm{j} \quad=$ medium $\mathrm{i}$ and $\mathrm{j}$

GO = a gratification obtainedrating on a scale for $\mathrm{i}$ and $\mathrm{j}$

$\mathrm{N} \quad=$ the number of respondents using a medium

$\mathrm{n} \quad=$ the first respondent

$\mathrm{K}=$ the number of scales on a dimension

$\mathrm{k}=$ the first gratification scale

Competitive Superiority is measured to identify which media is superior to others based on the utilization of the resources. It can be measured by the formula below.

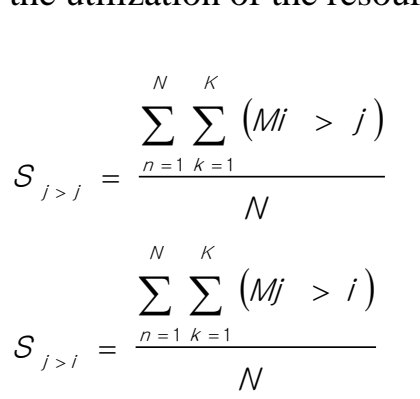

$\mathrm{i}, \mathrm{j} \quad=$ medium $\mathrm{i}$ and $\mathrm{j}$

$\mathrm{Mi}>\mathrm{j}=$ the value of a respondent's rating for those scale items on which $\mathrm{i}$ is rate greater than $\mathrm{j}$ (the sum of the actual values)

$\mathrm{Mj}>\mathrm{i}=$ the value of a respondent's rating for those scale items on which $\mathrm{j}$ is rate greater than $\mathrm{i}$ (the sum of the actual values)

$\mathrm{N}=$ the number of respondents who use both $\mathrm{i}$ and $\mathrm{j}$ 


$$
\begin{array}{ll}
\mathrm{n} & =\text { the first respondent } \\
\mathrm{K} & =\text { the number of scales on a dimension } \\
\mathrm{k} & =\text { the first gratification scale }
\end{array}
$$

\subsection{Definition of Important Factors}

As shown in the table below, the definitions of important factors that are used in this study are illustrated. These factors are employed to conduct the analysis of niche width, niche

\begin{tabular}{|c|c|c|}
\hline & Definition & Researchers \\
\hline $\begin{array}{l}\text { Information } \\
\text { Inquiry }\end{array}$ & $\begin{array}{l}\text { The degree of acquiring information and } \\
\text { knowledge using social media }\end{array}$ & $\begin{array}{l}\text { Kiel and Layton [10], } \\
\text { Beatty and Smith [1] }\end{array}$ \\
\hline $\begin{array}{c}\text { Social } \\
\text { Relationship }\end{array}$ & $\begin{array}{l}\text { Feelings and communication with others } \\
\text { using social media as well as sharing } \\
\text { interest with others }\end{array}$ & al. 112] \\
\hline $\begin{array}{c}\text { Social } \\
\text { Presence }\end{array}$ & $\begin{array}{l}\text { The degree of perception on the feelings of } \\
\text { humanness and friendliness as well as } \\
\text { feelings of others who make influences on } \\
\text { users }\end{array}$ & $\begin{array}{l}\text { Short et al. [14], } \\
\text { Leeret al. [15] }\end{array}$ \\
\hline $\begin{array}{l}\text { Media } \\
\text { Richness }\end{array}$ & $\begin{array}{l}\text { How well social media deal yith feedback, } \\
\text { language expressions and the ability to } \\
\text { represent feelings and perception of users. }\end{array}$ & $\begin{array}{l}\text { Carlson and Zmud [16] } \\
\text { Jiang et al. [5] }\end{array}$ \\
\hline
\end{tabular}
overlap, and superiority of social media.

Table 2. The Definitions of Factors

Information inquiry is designed as acquirng information and knowledge using social media. Collecting information about personal interests, hobbies, latest news, reports and professional areas is related to this factor Social Relations factor is designed as feelings and communication with others using social media as well as sharing interest with others. Social presence factor is involved with the degree of perception on the feelings of humanness and friendliness as welnas feelings of others who make influences on users. Richness of media factor is involved with how well social media deal with feedback, language expressions and the ability to represent feelings and perception of users. This factor is concerned about easiness to make questions, availability of functions such as a voice tone, gesture and icons and flexibility in languages.

\subsection{Data Collection and Characteristics of Samples}

Data collection was conducted to students who have experiences of using SNS. The questionnaire was distributed to students in Kazakhstan and Korean universities by either email or personal visit. The total number of questionnaires distributed was 200 and 117 questionnaires were collected. 103 out of 117 questionnaires were used to analyze the responses of users excluding incomplete and/ or inconsistent responses. Demographic characteristics of the samples are shown in Table 3. 
Table 3. Demographic Characteristics

\begin{tabular}{|c|c|c|c|c|c|c|c|}
\hline & & Number & $\%$ & & & Number & $\%$ \\
\hline \multirow{2}{*}{ Gender } & male & 37 & 35.9 & \multirow{5}{*}{$\begin{array}{c}\text { Work } \\
\text { experience }\end{array}$} & none & 55 & 53.4 \\
\hline & female & 66 & 64.1 & & $0 \sim 3$ years & 32 & 31.1 \\
\hline \multirow{4}{*}{ Age } & $20 \mathrm{~s}$ & 99 & 96.1 & & $3 \sim 5$ years & 6 & 5.8 \\
\hline & $30 \mathrm{~s}$ & 3 & 2.9 & & $5 \sim 10$ years & 8 & 7.8 \\
\hline & $40 \mathrm{~s}$ & 1 & 1.0 & & 10 and more & 2 & 1.9 \\
\hline & 50s and more & 1 & 0.2 & \multirow{6}{*}{ Profession } & Office clerk & 15 & 14.6 \\
\hline \multirow{4}{*}{$\begin{array}{l}\text { Edu- } \\
\text { cation }\end{array}$} & Below high school & 9 & 8.7 & & Sales/service & 6 & 5.8 \\
\hline & college & 82 & 79.6 & & $\begin{array}{c}\text { Research/profession } \\
\text { al }\end{array}$ & 3 & 2.9 \\
\hline & master & 10 & 9.7 & & Self-employed & 3 & 2.9 \\
\hline & doctoral & 2 & 1.9 & & student & 74 & 71.8 \\
\hline & & & & & Fulltime housewife & 2 & 1.97 \\
\hline
\end{tabular}

\section{Analysis of Research Findings}

\subsection{Reliability and Validity Analysis}

In order to measure the reliability of variables used in this study, Cronbach's Alpha test was conducted. As shown in the table below, Cronbach's Alpha coefficient $(\alpha)$ for Blog, Facebook, Twitter, Youtube was turned out to be greater than 0,6, which means the reliability of the variables is achieved. According to component analysis osing Varimax rotation, four factors were extracted as shown in the following table 4

Table 4. Reliability and Validity Analysis

\begin{tabular}{|c|c|c|c|c|}
\hline & & Facebook & Twitter & Youtube \\
\hline \multicolumn{5}{|l|}{ Factor 1: Information Inquiry } \\
\hline $\begin{array}{l}\text { the information about my interests } \\
\text { and hobbies using thismedia. }\end{array}$ & 0.877 & 0.806 & 0.817 & 0.688 \\
\hline $\begin{array}{l}\text { the information about professional } \\
\text { area using this media. }\end{array}$ & 0.801 & 0.884 & 0.831 & 0.710 \\
\hline $\begin{array}{l}\text { information about latest news and } \\
\text { reports using this media. }\end{array}$ & 0.675 & 0.797 & 0.718 & 0.704 \\
\hline Cronbach's alpha & 0.823 & 0.876 & 0.861 & 0.645 \\
\hline Eigen value & 2.245 & 2.610 & 2.650 & 2.386 \\
\hline Percentage of ariance explained & 18.706 & 21.753 & 22.084 & 19.881 \\
\hline \multicolumn{5}{|l|}{ Factor 2: Social Relationship } \\
\hline $\begin{array}{l}\text { share my eeling with others and } \\
\text { build sympathy using this media. }\end{array}$ & 0.839 & 0.702 & 0.737 & 0.841 \\
\hline $\begin{array}{l}\text { communicate with others using this } \\
\text { media. }\end{array}$ & 0.756 & 0.765 & 0.742 & 0.814 \\
\hline $\begin{array}{l}\text { know what others think and share my } \\
\text { interests with others using this media. }\end{array}$ & 0.752 & 0.820 & 0.803 & 0.654 \\
\hline Cronbach's alpha & 0.907 & 0.886 & 0.923 & 0.779 \\
\hline Eigen value & 2.428 & 2.308 & 2.444 & 2.210 \\
\hline Percentage of variance explained & 20.235 & 19.233 & 20.365 & 18.418 \\
\hline \multicolumn{5}{|l|}{ Factor 3: Social Presence } \\
\hline feel humaneness from this media. & 0.703 & 0.737 & 0.706 & 0.709 \\
\hline
\end{tabular}




\begin{tabular}{|c|c|c|c|c|}
\hline feel friendly from this media. & 0.745 & 0.681 & 0.726 & 0.651 \\
\hline $\begin{array}{l}\text { feel how others who make influences } \\
\text { on me feel from this media. }\end{array}$ & 0.765 & 0.814 & 0.784 & 0.715 \\
\hline $\begin{array}{l}\text { feel like having a private } \\
\text { conversation with others while using } \\
\text { this media. }\end{array}$ & 0.840 & 0.760 & 0.860 & 0.825 \\
\hline Cronbach's alpha & 0.863 & 0.832 & 0.868 & 0.794 \\
\hline Eigen value & 2.783 & 2.629 & 2.934 & 2.386 \\
\hline Percentage of variance explained & 23.193 & 21.907 & 24.453 & 19.881 \\
\hline \multicolumn{5}{|l|}{ Factor 4: Media Richness } \\
\hline $\begin{array}{l}\text { express user's feeling and emotion on } \\
\text { either negative or positive problems. }\end{array}$ & 0.729 & 0.735 & 0.731 & \\
\hline $\begin{array}{l}\text { flexible in the way of using languages } \\
\text { to improve the understanding. }\end{array}$ & 0.822 & 0.853 & 0.831 & \\
\hline Cronbach's alpha & 0.630 & 0.692 & $0.04+9$ & 0.6 \\
\hline Eigen value & 1.807 & 1.661 & 1.520 & 1.647 \\
\hline Percentage of variance explained & 15.061 & 13.838 & 12.667 & 13.728 \\
\hline
\end{tabular}

\subsection{Results of Niche Analysis}

Niche breadth is a standardized number, ranged $0 \sim 1$, indicating the level of satisfaction for a particular factor. The closer the niche breadth is to 1 , the more the media is satisfied by users. It was revealed that Youtube and Facebook were considered to be widely accepted in terms of information inquiry factor. Only lacebook was chosen in terms of social relation factor and all the media are considered to be satisfactory for richness of media factor. Finally, all media were not to be satisfactory for feelings of social existence factor since their niche breadth indicated less than 0.5 .

Table 5. Wiche Breadth

\begin{tabular}{|c|c|c|c|c|}
\hline & B $10 g(\mathrm{~B})$ & Facebook(F) & Twitter(T) & Youtube(Y) \\
\hline Information inquiry(II) & 0.487 & 0.511 & 0.406 & 0.672 \\
\hline Social Relationship(SR) & 0.401 & 0.618 & 0.418 & 0.376 \\
\hline Social Presence(SP) & 0.371 & 0.466 & 0.373 & 0.427 \\
\hline Media richness(MR) & 0.550 & 0.651 & 0.582 & 0.651 \\
\hline
\end{tabular}

Niche overlap deals with the degree of competency between two media over common resources or customers. The smaller the value of niche overlap, the higher the degree of competency exists. The high value of niche overlap indicates that the two media are independent each other. This research used 7 points scale which is ranged from 0 to 6 . It was noticed that there was a competency between Twitter and Blog in terms of richness of media factor. It was also observed that Youtube and Facebook have competency relationship in terms of richness of media.

Table 6. Niche Overlap

\begin{tabular}{|c|c|c|c|c|c|c|}
\hline & B:F & B:T & B:Y & F:T & F:Y & T:Y \\
\hline II & 2.035 & 2.220 & 2.982 & 2.270 & 2.775 & 3.318 \\
\hline
\end{tabular}




\begin{tabular}{|c|c|c|c|c|c|c|}
\hline SR & 3.066 & 1.710 & 2.113 & 2.859 & 3.195 & 2.018 \\
\hline SP & 2.063 & 1.272 & 2.019 & 2.199 & 1.859 & 1.680 \\
\hline MR & 1.627 & 1.105 & 1.709 & 1.538 & 1.400 & 1.579 \\
\hline
\end{tabular}

Superiority determines the level of competency of social media. It measures how social media are dependent upon each other to satisfy user's requirement and expectations. Therefore, superiority tells relative competency level compare to other social media.

Table 7. Superiority

\begin{tabular}{|c|c|c|c|c|c|c|c|c|c|c|c|c|}
\hline & \multicolumn{2}{|c|}{$\mathrm{B}: \mathrm{F}$} & \multicolumn{2}{|c|}{$\mathrm{B}: \mathrm{T}$} & \multicolumn{2}{|c|}{$\mathrm{B}: \mathrm{Y}$} & \multicolumn{2}{|c|}{$\mathrm{F}: \mathrm{T}$} & \multicolumn{2}{|c|}{$F: Y$} & \multicolumn{2}{|c|}{$\mathrm{T}: \mathrm{Y}$} \\
\hline & $\mathrm{B}>\mathrm{F}$ & $\mathrm{F}>\mathrm{B}$ & $\mathrm{B}>\mathrm{T}$ & $\mathrm{T}>\mathrm{B}$ & $\mathrm{B}>\mathrm{Y}$ & $Y>B$ & $\mathrm{~F}>\mathrm{T}$ & $\mathrm{T}>\mathrm{F}$ & $\mathrm{F}>\mathrm{Y}$ & $Y>F$ & $T>Y$ & $Y>T$ \\
\hline \multirow{3}{*}{ II } & 4777 & 5360 & 6146 & 3524 & 3.35 & 9.14 & 5.91 & 2.68 & 3.53 & 8.62 & $2 .{ }^{2}$ & 10.68 \\
\hline & 4.171 & 5.369 & 0.146 & 3.524 & 9 & 6 & 3 & 9 & 4 & 1 & & 0 \\
\hline & \multicolumn{2}{|c|}{$t=-0.630$} & \multicolumn{2}{|c|}{$\mathrm{t}=2.886^{*} * *$} & \multicolumn{2}{|c|}{$\mathrm{t}=-5.495 * * *$} & \multicolumn{2}{|c|}{$\mathrm{t}=3.461 * * *$} & \multicolumn{2}{|c|}{$\mathrm{t}=-4.828 * * *$} & \multicolumn{2}{|c|}{$\mathrm{t}=-9.280 * * *$} \\
\hline \multirow{3}{*}{ SR } & 1942 & 8592 & 3214 & 3738 & 4.50 & 3.28 & 8.05 & & 9.73 & & 4.82 & 3000 \\
\hline & & 0.092 & & & & 2 & & & & & 5 & \\
\hline & \multicolumn{2}{|c|}{$\mathrm{t}=-7.079 * * *$} & \multicolumn{2}{|c|}{$t=-0.599$} & \multicolumn{2}{|c|}{$\mathrm{t}=1.341$} & & & \multicolumn{2}{|c|}{$\mathrm{t}=8.309 *$ * $*$} & \multicolumn{2}{|c|}{$\mathrm{t}=1.995 * *$} \\
\hline \multirow{3}{*}{ SP } & 2825 & 6.748 & 3.369 & 3.204 & 3.74 & 5.74 & & 2.79 & & 3.98 & 3.43 & 5340 \\
\hline & 2.825 & 0.148 & 3.509 & 5.204 & 8 & 8 & & 6 & & 1 & 7 & \\
\hline & \multicolumn{2}{|c|}{$\mathrm{t}=-3.640 * * *$} & \multicolumn{2}{|c|}{$\mathrm{t}=0.195$} & \multicolumn{2}{|c|}{$\mathrm{t}=-1.866^{*}$} & \multicolumn{2}{|c|}{$\mathrm{t}=4.449 * * *$} & \multicolumn{2}{|c|}{$\mathrm{t}=2.026^{* * *}$} & \multicolumn{2}{|c|}{$\mathrm{t}=-2.061 * *$} \\
\hline \multirow{2}{*}{ MR } & 1.952 & 3.757 & 1.786 & 2.553 & & & 358 & $1.79^{\circ}$ & 2.59 & 2.83 & 2.09 & 3.621 \\
\hline & \multicolumn{2}{|c|}{$\mathrm{t}=-2.842 * * *$} & \multicolumn{2}{|c|}{$\mathrm{t}=-1.480$} & \multicolumn{2}{|c|}{$3.090 * * *$} & & $6 * *$ & \multicolumn{2}{|c|}{$\mathrm{t}=-0.370$} & \multicolumn{2}{|c|}{$\mathrm{t}=-2.490 * *$} \\
\hline
\end{tabular}

(P* $=0.1, \mathrm{P} * 0.05, \mathrm{P} * *=0.01)$

Information described in the abovetables can be summarized as follows.

Information inquiry : Youtubo > Facebook $=$ Blog $>$ Twitter

Social Relationship : Facebook $>$ Twitter $=$ Blog $>$ Youtube

Social Presence : Facebook $>$ Youtube $>$ Twitter $=$ Blog

Media richness : Yputube $>$ Faceb oo $>$ Twitter $=$ Blog

\section{Conclusion}

This study examinedgratification of social media utilizing limited resources based on four important factors uning niche theory. Niche theory employs niche width, niche overlap, and superiority to analyze the degree of competency of each social media based on each criteria.

With regard to information inquiry factor, Youtube and Facebook are turned out to be greater than 05, meaning that they are better media fulfilling user's requirements while Facebook is only chosen as a social media satisfying user's needs in terms of social relations factor. With regard to feeling of social presence factor, all four social media end up with less than 0.5 , indicating that they are not satisfying user's needs. It is concluded that all four social media are not widely used for this purpose. Finally, for richness of media factor, all four media received greater than 0.5 , which means that they are well fulfilling user's expectation.

As discussed before, niche overlap indicates the competent relationship between two social media. The result of data analysis revealed that the value of niche overlap was turned out to be greater than 2.0, meaning all four social media are doing well in terms of information inquiry factor. On the other hand, the value of niche overlap on the richness of the media factor was less than 1.0, indicating that all four media are competing each other in this category. 
The relative competency of the social media is measured by the superiority. The result of the data analysis showed that Facebook was turned out to be most superior to other social media since it has ranked either first or second in all factors. Youtube was very superior to other media on information inquiry factor. It is generally understood that Youtube is video content oriented and more popular to share new information and communicate with others rather than building networks and sharing feelings with others. The superiority of Youtube was especially very low in social relations factor. The superiority of Twitter was very high on social relations factor. It reflects the fact that Twitter is using short sentences to communicate with other users and easy to share the opinions and thoughts comparing to Blog and Youtube. The study revealed that Blog was turned out to be weak in terms of superiority category even if it has a lot of advantages to use sentences, video, animation, and feedback from other users.

The limitation of this study is basically dependent upon samples from university students. Consequently, it seems to be difficult to generalize the result of the study to apply to all user groups representing diverse age groups. It is desirable and recommended to conduct further research to specify the level of previous experiences and consider personal characteristics.

\section{Reference}

[1] M. Kaplan and M. Haenlein, "Users of the world, unite! The challenges and opportunities of Social Media”, Business horizons vol. 53, no. 1, (2010), pp. 59-68.

[2] R. Grieve, M. Indian, K. Witteveen, G. Anne Tolan and J. Marrington, "Face-to-face or Facebook: Can social connectedness be derived online?", Computer in Human Behavior, vol. 29, no. 3, (2013), pp. 604609.

[3] M. Thelwall, K. Buckley and G. Paltoglou, "Sentiment in Twitter events. Journal of the American Society for Information”, Science and Technology, 01,62, no. 2, (2011),pp. 406-418.

[4] R. L. Daft, R. H. Lengel and L. K. Trevino, "Message equivocality, media selection, and manager performance: Implications for informa10n systems", MIS quarterly, vol. 11, no. 3, (1987), pp. 355-366.

[5] Z. Jiang, C. S. Heng and B. C. Choi "Research Note-Privacy Concerns and Privacy-Protective Behavior in Synchronous Online Social Interactions", Information Systems Research, vol. 2, no. 3, (2013), pp. 579-595.

[6] F. Biocca, C. Harms and J. Burgoon, "Toward a more robust theory and measure of social presence: Review and suggested criteria”, Presence, vol. 12, no. 5, (2003), pp. 456-480.

[7] C. Xu, S. Ryan, V. Prybutok and C. Wen, "It is not for fun: An examination of social network site usage", Information \& Management vol. 49, no. 5 (2012), pp. 210-217.

[8] J. Dimmick, Y. Chen and Z. Li, "Competition between the Internet and traditional news media: The gratification-opportunities niche dimension”, The Journal of Media Economics, vol. 17, no. 1, (2004), pp. 19-33.

[9] J. Dimmick S Kline and L. Stafford, "The gratification niches of personal e-mail and the telephone competition, displacement and complementarity", Communication Research, vol. 27, no. 2, (2000), pp. 227 248.

[10] G. C. Kiel and R.A. Layton, "Dimensions of consumer information seeking behavior", Journal of marketing Research, vo. 18, no 2, (1981), pp. 233-239.

[11] S. E. Beatty and S. M. Smith, "External search effort: An investigation across several product categories", Journal of consumer research, vol. 14, no. 1, (1987), pp. 83-95.

[12] M. D. Roblyer, M. McDaniel, M. Webb, J. Herman and J. V. Witty, "Findings on Facebook in higher education: A comparison of college faculty and student uses and perceptions of social networking sites", The In ternet and Higher Education, vo. 13, no. 3, (2010), pp. 134-140.

[13] E. Fischer and A. R. Reuber, "Social interaction via new social media:(How) can interactions on Twitter affect effectual thinking and behavior?", Journal of business venturing, vol. 26, no. 1, (2011), pp. 1-18.

[14] J. Short, E. Williams and B. Christie, The social psychology of telecommunications, (1976).

[15] Y. Lee, K. A. Kozar and K. R. Larsen KR, "Avatar e-mail versus traditional e-mail: Perceptual difference and media selection difference", Decision Support Systems, vol. 46, no. 2, (2009), pp. 451-467.

[16] J. R. Carlson and R. W. Zmud, "Channel expansion theory and the experiential nature of media richness perceptions", Academy of management journal, vol. 42, no. 2, (1999), pp. 153-170. 


\section{Authors}

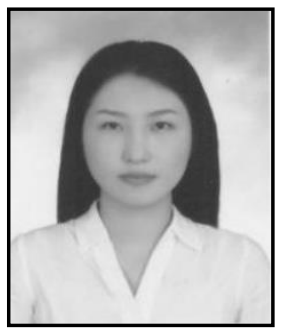

Heon Baek received a B.S degree and the M.S. degree in Management Information System from the Catholic University of Daegu in 2004, and 2012 repectively. She is a Ph.D. Student majoring in Management Information System at the Sogang University, Korea. Her research interests include social networking, datamining.

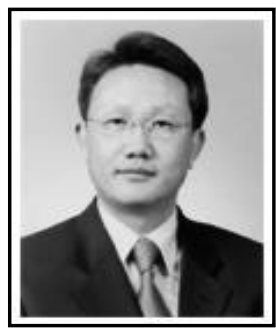

Dr. Ha Jin Hwang is Full Professor of Operations Management and Information Systems and Dean of Bang College of Business, KIMEP University, Kazakhstan. He received Ph.D. (MIS) from Mississippi State University and taught a Minnesota State University(1989-1991), U.S.A. and Catholic University of Daegu(1991-2010), Korea. He also served as President of Korea Association of Information Systems(2005) and President of Korea Internet Electronic Commerce Association(2008). His research interests include supply chain mahagement systems, e-Business applications, and social networking.

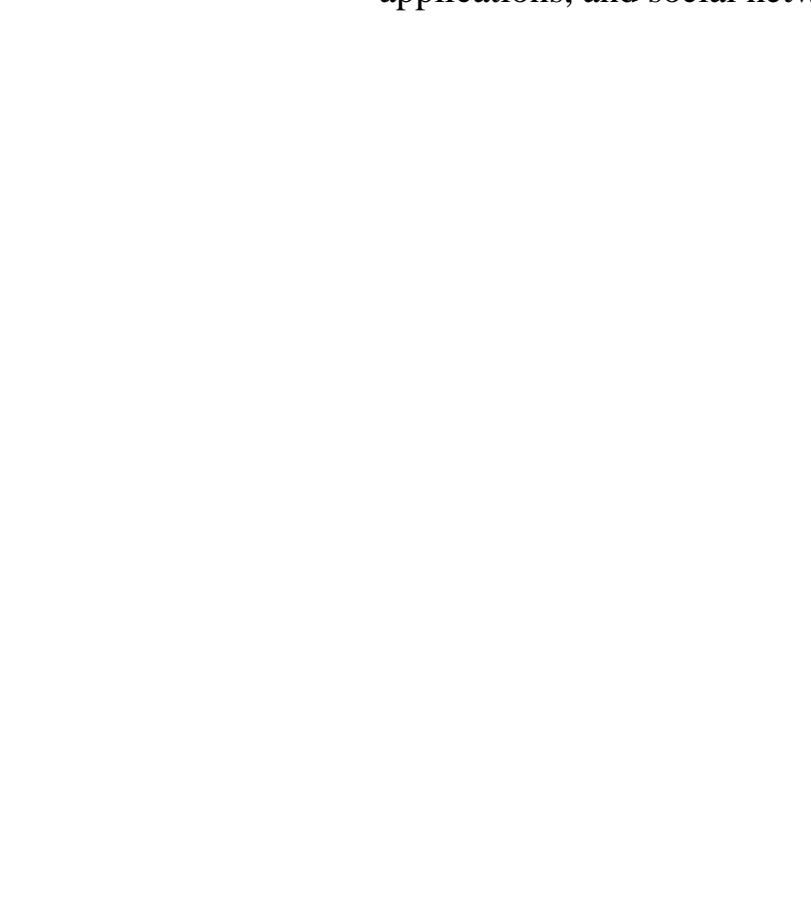

